STRUCTURAL BIOLOGY COMMUNICATIONS

ISSN 2053-230X
Received 12 October 2015

Accepted 15 January 2016

Edited by N. Sträter, University of Leipzig, Germany

Keywords: improved diffraction resolution; raw diffraction images.; re-refinement; cisplatin; histidine; addendum.

PDB reference: re-refinement of $4 \mathrm{~g} 4 \mathrm{a}, 5 \mathrm{hll}$

Supporting information: this article has supporting information at journals.iucr.org/f

\section{Re-refinement of 4g4a: room-temperature X-ray diffraction study of cisplatin and its binding to His15 of HEWL after 14 months chemical exposure in the presence of DMSO}

Simon W. M. Tanley, ${ }^{a}$ Antoine M. M. Schreurs, ${ }^{b}$ Loes M. J. Kroon-Batenburg ${ }^{b}$ and John R. Helliwell ${ }^{\mathrm{a} *}$

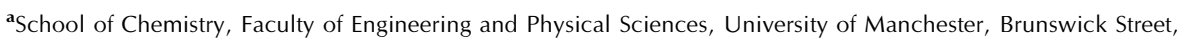
Manchester M13 9PL, England, and ${ }^{\mathbf{b}}$ Crystal and Structural Chemistry, Bijvoet Center for Biomolecular Research, Faculty of Science, Utrecht University, Padualaan 8, $3584 \mathrm{CH}$ Utrecht, The Netherlands. *Correspondence e-mail: john.helliwell@manchester.ac.uk

A re-refinement of $4 \mathrm{~g} 4 \mathrm{a}$, the room-temperature X-ray diffraction study of cisplatin and its binding to His15 of HEWL after 14 months chemical exposure in the presence of DMSO is published as an addendum to Tanley et al. [(2012), Acta Cryst. F68, 1300-1306]. This example illustrates the benefits of sharing raw diffraction images, as well as structure factors and molecular coordinates, as the diffraction resolution of the study is now much improved at $1.70 \AA$.

We have re-refined our previously published room temperature crystal structure of cisplatin binding to hen egg lysozyme (PDB entry 4g4a; Tanley et al., 2012) at a resolution of $1.7 \AA$. This structure was originally refined by us at $2.4 \AA$ resolution and subsequently re-refined by Shabalin et al. (2015) to $2.0 \AA$ resolution. Both studies extended the diffraction resolution by reprocessing subsets of the same data set's raw diffraction images [originally held at Utrecht University; Tanley et al. (2013) and which are now accessible at the University of Manchester (Tanley \& Helliwell, 2015)]. Shabalin et al. (2015) (PDB code 4yen) interpreted the platinum coordination spheres as $\left[\mathrm{PtCl}_{3} \mathrm{His} 15\right]$ for the platinum ion $\left(\mathrm{Pt}^{\delta}\right)$ coordinated
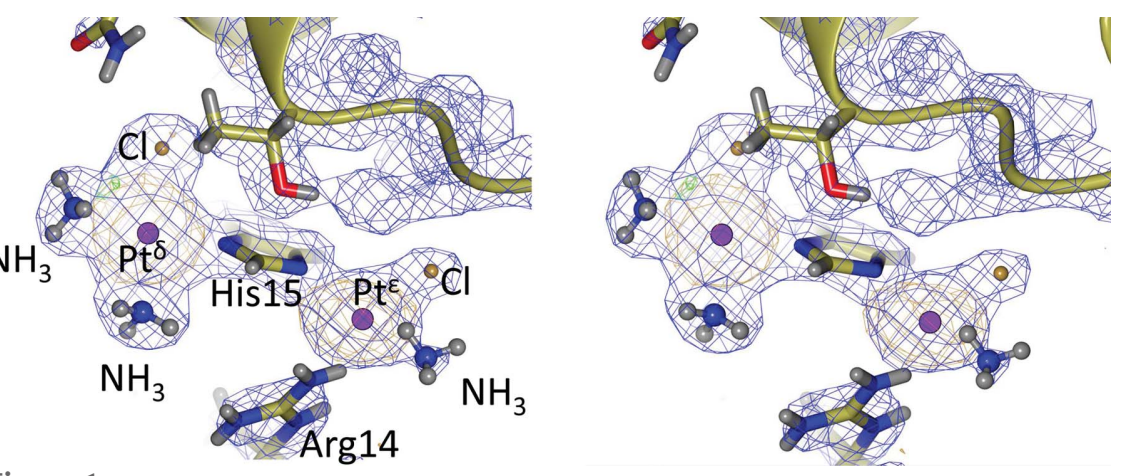

Figure 1

Stereo image of the cisplatin coordination to His15. A platinum ion is bound to both the $\mathrm{N}^{\delta}$ and $\mathrm{N}^{\varepsilon}$ sides of the imidazole ring with ligands (two ammines and one $\mathrm{Cl}$ atom at $\mathrm{Pt}^{\delta}$, and one chlorine, one ammine and the $\operatorname{Arg} 14$ side chain at $\left.\mathrm{Pt}^{\varepsilon}\right)$. Electron-density maps: $2 F_{\mathrm{o}}-F_{\mathrm{c}}$ (in blue at 1.0 r.m.s.), $F_{\mathrm{o}}-F_{\mathrm{c}}$ (in green at $5.0 \sigma$ ) and anomalous difference Fourier map (in orange at $3.0 \sigma$ ) of the final model. The two platinum ions are depicted in purple, the $\mathrm{Cl}$ atoms in brown, the $\mathrm{N}$ atoms in blue, $\mathrm{O}$ atoms in red and $\mathrm{H}$ atoms in charcoal grey. The orientation of each ammine's three $\mathrm{H}$ atoms and of the Arg14 side-chain $\mathrm{H}$ atoms at $1.7 \AA$ diffraction resolution are obviously approximate (the Arg14 side-chain nitrogen closest to the $\mathrm{Pt}^{\varepsilon}$ in particular would present a lone pair of electrons to the metal atom). This figure was prepared using CCP4mg (McNicholas et al., 2011). 
to $\mathrm{N}^{\delta}$ of His15 and $\left[\mathrm{PtCl}_{2} \mathrm{His} 15 \mathrm{Arg} 14\right]$ for the second platinum ion $\left(\mathrm{Pt}^{\varepsilon}\right)$ bound to His15- $\mathrm{N}^{\varepsilon}$. A re-refinement of $4 \mathrm{~g} 4 \mathrm{a}$ at the extended resolution of $1.7 \AA$ presented here gives improved clarity, and a small spread of $B$ factors, of the $\mathrm{Pt}$ ligand assignments which are $\left[\mathrm{PtClNH}_{3} \mathrm{NH}_{3} \mathrm{His} 15\right]$ for $\mathrm{Pt}^{\delta}$, and [PtClNH ${ }_{3}$ His15Arg14] for $\mathrm{Pt}^{\varepsilon}$; see Fig. 1. Details are provided in the Supporting Information.

The following references are cited in the Supporting Information for this article: Afonine et al. (2012); Casini et al. (2007); Diederichs \& Karplus (2013); Joosten et al. (2014); Murshudov et al. (1997); Schreurs et al. (2010); Tanley, Schreurs, Kroon-Batenburg, Meredith et al. (2012); Tanley et al. (2015).

\section{Acknowledgements}

We thank Shabalin et al. (2015) for their valuable critique and to which we responded (Tanley et al., 2015). SWMT was funded under an EPSRC PhD Research Studentship at the School of Chemistry, University of Manchester.

\section{References}

Afonine, P. V., Grosse-Kunstleve, R. W., Echols, N., Headd, J. J., Moriarty, N. W., Mustyakimov, M., Terwilliger, T. C., Urzhumtsev,
A., Zwart, P. H. \& Adams, P. D. (2012). Acta Cryst. D68, 352367.

Casini, A., Mastrobuoni, G., Temperini, C., Gabbiani, C., Francese, S., Moneti, G., Supuran, C. T., Scozzafava, A. \& Messori, L. (2007). Chem. Commun. 156-158.

Diederichs, K. \& Karplus, P. A. (2013). Acta Cryst. D69, 1215-1222.

Joosten, R. P., Long, F., Murshudov, G. N. \& Perrakis, A. (2014). IUCrJ, 1, 213-220.

McNicholas, S., Potterton, E., Wilson, K. S. \& Noble, M. E. M. (2011). Acta Cryst. D67, 386-394.

Murshudov, G. N., Vagin, A. A. \& Dodson, E. J. (1997). Acta Cryst. D53, 240-255.

Schreurs, A. M. M., Xian, X. \& Kroon-Batenburg, L. M. J. (2010). J. Appl. Cryst. 43, 70-82.

Shabalin, I., Dauter, Z., Jaskolski, M., Minor, W. \& Wlodawer, A. (2015). Acta Cryst. D71, 1965-1979.

Tanley, S. W. M. , Diederichs, K., Kroon- Batenburg, L. M. J. , Levy, C., Schreurs, A. M. M. \& Helliwell, J. R. (2015). Acta Cryst. D71, 1982-1983.

Tanley, S. W. M. \& Helliwell, J. R. (2015). https://www.escholar. manchester.ac.uk/uk-ac-man-scw:215887. doi: 10.15127/1.215887.

Tanley, S. W. M., Schreurs, A. M. M., Helliwell, J. R. \& KroonBatenburg, L. M. J. (2013). J. Appl. Cryst. 46, 108-119.

Tanley, S. W. M., Schreurs, A. M. M., Kroon-Batenburg, L. M. J. \& Helliwell, J. R. (2012). Acta Cryst. F68, 1300-1306.

Tanley, S. W. M., Schreurs, A. M. M., Kroon-Batenburg, L. M. J., Meredith, J., Prendergast, R., Walsh, D., Bryant, P., Levy, C. \& Helliwell, J. R. (2012). Acta Cryst. D68, 601-612. 